\title{
The Role of Antioxidant Vitamin C on Imminent Abortion through Interaction of Superoxide Dismutase, Interferon- $\gamma$, Interleukin-4, Vascular Cells Adhesion Molecule-1, and Decidual Spiral Arteries Blood Flow
}

\author{
Budi Handono $^{1}$, Firman F. Wirakusumah1, Johanes C. Mose ${ }^{1}$, Tri Hanggono Achmad ${ }^{2}$ \\ ${ }^{1}$ Department of Obstetrics and Gynecology, Faculty of Medicine, Padjadjaran University/Hasan Sadikin Hospital, \\ Bandung, Indonesia \\ ${ }^{2}$ Department of Biochemistry, Faculty of Medicine, Padjadjaran University/Hasan Sadikin Hospital, Bandung, \\ Indonesia \\ Email: budihandono9@yahoo.com
}

Received 13 January 2015; accepted 11 February 2015; published 13 February 2015

Copyright (C) 2015 by authors and Scientific Research Publishing Inc.

This work is licensed under the Creative Commons Attribution International License (CC BY). http://creativecommons.org/licenses/by/4.0/

(c) (7) Open Access

\begin{abstract}
Imminent abortion needs more serious attention since it remains a big problem in Indonesia considering its epidemiology, morbidity, mortality, and prognosis. In fact, some cases can still be prevented. The objective of this study was to determine pathogenesis, diagnosis, and prognosis of imminent abortion through the role of antioxidant vitamin $\mathrm{C}$ in the interaction of superoxide dismutase (SOD), interferon- $\gamma$ (IFN- $\gamma$ ), interleukin-4 (IL-4), vascular cells adhesion molecule-1 (VCAM1), and decidual spiral artery resistance index (DSA RI). This study took 10 months from March to December 2007 at Obstetrics and Gynecology Department of Medical Faculty of Padjadjaran University/Hasan Sadikin Hospital, Bandung. Sixty pregnant women who met the inclusion and exclusion criteria were divided into two groups with the random clinical trial method, double-blind with repeated measurements. Data were analyzed statistically using $t$ test, Mann-Whitney, Rank Spearman, Wilcoxon, $t$ paired, and diagnostic test. The results of this study showed that the incidence of abortion in vitamin $C$ group was 9 cases $(30 \%)$ and placebo group was 13 cases (43.3\%). There was a significant difference in SOD, IFN- $\gamma$, IL-4 and VCAM-1 level between groups of women with and without abortion $(p<0.001)$. There was a significant difference of SOD level between women with abortion $655.8(163.6) \mathrm{U} / \mathrm{gHb}$ and placebo group 824.5 (106.7) $\mathrm{U} / \mathrm{gHb}$ after vitamin C
\end{abstract}

\footnotetext{
"Corresponding author.
}

How to cite this paper: Handono, B., Wirakusumah, F.F., Mose, J.C. and Achmad, T.H. (2015) The Role of Antioxidant Vitamin C on Imminent Abortion through Interaction of Superoxide Dismutase, Interferon- $\gamma$, Interleukin-4, Vascular Cells Adhesion Molecule-1, and Decidual Spiral Arteries Blood Flow. Open Journal of Obstetrics and Gynecology, 5, 103-114. 
administration ( $p=0.008$ ). The cutoff point of SOD was $\leq 992 \mathrm{U} / \mathrm{gHb}$ which showed quite high sensitivity, specificity, accuracy, and significant difference $(p<0.001)$. The cutoff point abortion of DSA resistance index was $\geq 0.55$ with $45 \%$ accuracy $(p=0.002)$. The highest change of IL-4 level was $60.7 \%$ in vitamin $C$ group and VCAM-1 was $-2.2 \%(p<0.05)$ after vitamin $C$ administration. There was a negative correlation in SOD changes toward IL-4 changes after vitamin C administration $(r=-0.523)(p=0.003)$, a positive correlation between SOD changes and IL-4 changes (0.597) $(p<0.001)$, a negative correlation between SOD changes and VCAM-1 changes $(r=-0.737)(p<$ $0.001)$ and a negative correlation between SOD changes and DSA RI changes $(r=-0.208)(p=$ $0.022)$. There were significant changes in the increment of IL-4 and SOD level $(p<0.001)$ and a decline in IFN- $\gamma$, VCAM-1 and DSA RI $(p<0.001)$ before and after vitamin C administration. In conclusion, there was a correlation between the increase of SOD level with the decrease of INF- $\gamma$ level and the increase of IL-4 level in imminent abortion after vitamin $C$ administration. There was a correlation between the increase of SOD level with the decrease of DSA RI and the decrease of VCAM-1 level in imminent abortion after vitamin $\mathrm{C}$ administration. In abortion, there was a decrease of SOD and IL-4 level, as well as an increase of IFN- $\gamma$, VCAM-1, and DSA RI level.

\section{Keywords}

Imminent Abortion, SOD, VCAM-1, IFN- $\gamma$, IL-4, DSA RI

\section{Introduction}

Imminent abortion requires serious attention, since it is still a major problem in Indonesia in terms of epidemiology, morbidity, mortality, and prognosis. In some cases, imminent abortion still can be prevented [1] [2]. Unclear etiology and pathogenesis due to the absence of treatment that is able to detect as early as possible and prevent the incidence of abortion is one of the causes of the prevention failure of this disease. Information about the mechanism of action and the effect of vitamin $\mathrm{C}$ as an antioxidant on the pathogenesis of imminent abortion, especially concerning the changes in the balance between embryotoxic Th1 pathway (i.e. IFN- $\gamma$ ) and Th2 pathway (i.e. IL-4) and a decrease in SOD level due to electrons excitation from the mitochondrial respiratory chain and the presence of DSA damage, which is characterized by the dysfunction of endothelial adhesion molecules i.e. VCAM-1 and the changes in blood flow, has led to the study of the drug as a potential preventive treatment against this disease.

This research was aimed to find a way of treatment to prevent imminent abortion into abortion and understand its mechanism of action. The results were expected to provide useful informations for scientific understanding development about the pathogenesis of imminent abortion related to decidual cell membrane damage characterized by the changes in the levels of SOD, VCAM-1, IFN- $\gamma$, IL-4, and the changes in DSA blood flow which arouse the interest for further research. These results were also expected to improve the prevention effort of maternal morbidity and mortality due to imminent abortion, and to improve the quality of Indonesian human resources in general.

\section{Methods}

This study used an interventional/clinical trials with randomized placebo controlled, double-mask study and analysis of variance (ANOVA) with repeated measures. This research was performed in Obstetrics and Gynecology Department of Hasan Sadikin Hospital Bandung in cooperation with Prodia laboratory, within 10 months, and had been approved by the ethical committee of Medical Faculty of Padjadjaran University Bandung.

The subjects were 60 pregnant women with a diagnosis of imminent abortion, which met the inclusion criteria. The inclusion criteria included all pregnancies with a diagnosis of imminent abortion, living singleton pregnancies, gestational age of 10 - 12 weeks, maternal age less than 30 years old, normal range of maternal body mass index (18 - $\left.25 \mathrm{~kg} / \mathrm{m}^{2}\right)$, maternal clear address and accesibility. The exclusion criteria were fetal congenital abnormalities, uterine abnormalities, maternal antioxidant drugs consumption, hormonal abnormalities, placen- 
totropic, maternal smoking and alcohol drinking habit, maternal tough job, hyperemesis gravidarum, history of infectious diseases, chronic diseases such as kidney disease, heart disease, hypertension, diabetes mellitus, hypothyroidism, peptic ulcer, not taking the medicine more than two days (as seen from the use of medication adherence log books), consumption of other medications instead of the study protocol.

In this study, there were two groups of pregnant women that were given vitamin $\mathrm{C}$ and placebo respectively. The number of samples was determined by using the sample size formula for testing two proportions, so the minimum estimation required for this study was 27 for each group. Taking into account the likely numbers of drop out (out of the study) by $10 \%$, then 30 pregnant women were obtained for each group.

Samples selection were performed using stratified random sampling, whereas candidates determination of control and treatment group were done using permuted-block randomization. The observation units were all imminent abortion that met the inclusion criteria of the study. The samples were determined on the basis of the selection criteria and according to the random numbers which were then saved in sealed envelopes.

Clinical examination of DSA RI was performed with ultrasound Medison SA 8000 3D. The levels of SOD were measured in laboratory using spectrophotometer, whereas IFN- $\gamma$, IL-4, and VCAM- 1 were examined using ELISA method in Health Research Laboratory Unit of Medical Faculty of Padjadjaran University/Hasan Sadikin Hospital Bandung and Prodia Laboratory.

Statistical analysis was performed using SPSS/PC+ version 13.0. Statistical tests of significance was determined based on the $\mathrm{p}$ value $<0.05$. The statistical test used to compare the average of two groups was t test. The mean differences of variables in the two groups were calculated using the Mann-Whitney test. Spearman rank correlation test was used to see the variables changes in two groups of study. Wilcoxon test was used to compare the treatment toward variables. Paired t test was used to compare the average of the two groups that were paired. Diagnostic test was used to determine the intersection point (cutoff point), sensitivity, specificity, and accuracy of various variables in the two groups.

\section{Results}

This study lasted for 10 months, from March to December 2007. Selection of patients were made within 7 months. During this time as many as 130 pregnant women with a diagnosis of imminent abortion were examined and as many as 60 cases met the inclusion criteria. Once the study was completed, there was no case of drop out. There were no side effects of the actions performed on the patients in accordance with the study protocol. There were no toxic effects or maternal deaths due to vitamin $\mathrm{C}$ during this study. There were no significant side effects that led to discontinuation of vitamin $\mathrm{C}$ or required other special actions at the time of this study.

Table 1 shows that in terms of the characteristics of the study subjects, both maternal age and gestational age and parity, there was no significant difference between vitamin $C$ and placebo groups. Based on the data homogeneity, the two groups were feasible to be compared.

Table 1. Subjects' characteristics.

\begin{tabular}{|c|c|c|c|c|}
\hline \multirow[b]{2}{*}{ Characteristics } & \multicolumn{2}{|c|}{ Treatments } & \multirow[b]{2}{*}{$\mathrm{t}$} & \multirow[b]{2}{*}{$\mathrm{p}$ values } \\
\hline & $\begin{array}{c}\text { Vitamin C } \\
(\mathrm{n}=30)\end{array}$ & $\begin{array}{l}\text { Placebo } \\
(n=30)\end{array}$ & & \\
\hline \multicolumn{5}{|c|}{ Maternal age (year) } \\
\hline$x(S D)$ & $25.6(3.8)$ & $25.8(3.2)$ & \multirow{2}{*}{0.78} & \multirow{2}{*}{0.437} \\
\hline Range & $19-30$ & $18-30$ & & \\
\hline \multicolumn{5}{|c|}{ Gestational age (week) } \\
\hline $\mathrm{x}(\mathrm{SD})$ & $10.8(0.8)$ & $10.9(0.9)$ & \multirow{2}{*}{0.30} & \multirow{2}{*}{0.769} \\
\hline Range & $10-12$ & $10-12$ & & \\
\hline \multicolumn{5}{|l|}{ Parity } \\
\hline $0 \mathrm{~s}$ & 16 & 16 & & \multirow{4}{*}{1.0} \\
\hline 1 & 9 & 9 & & \\
\hline 2 & 4 & 4 & & \\
\hline 3 & 1 & 1 & & \\
\hline
\end{tabular}

$\mathrm{t}=\mathrm{t}$ test. 
Table 2 shows a comparison of the two groups' variables. There was a significant difference in the levels of SOD of abortion group that occured after vitamin C administration compared to placebo administration.

Table 3 presents the point of intersection of various variables that were measured to predict the occurrence of abortion based on ROC curve. The cut point of SOD, IFN- $\gamma$, IL-4 and VCAM-1 levels show the sensitivity, specificity, and accuracy that are quite high, while the DSA RI has a high sensitivity but low specificity.

Table 4 shows the groups after vitamin $\mathrm{C}$ administration. There are significant differences in the increase of IL-4 levels' percentage and the decrease of VCAM-1 levels' percentage.

Table 2. Comparison of various variables in the two study groups after vitamin $\mathrm{C}$ and placebo administration.

\begin{tabular}{|c|c|c|c|}
\hline Variables & Vitamin C & Placebo & Significance \\
\hline \multicolumn{4}{|l|}{ Abortion } \\
\hline $\mathrm{n}$ & 9 & 13 & \\
\hline \multicolumn{4}{|c|}{$\mathrm{SOD}(\mathrm{U} / \mathrm{gHb})$} \\
\hline $\mathrm{x}(\mathrm{SD})$ & 655.8 (163.6) & 824.5 (106.7) & \multirow{3}{*}{$\begin{array}{c}\mathrm{t}=2.94 \\
\mathrm{p}=0.008\end{array}$} \\
\hline Range & $460-983$ & $598-992$ & \\
\hline Median & 659 & 835 & \\
\hline \multicolumn{4}{|c|}{ IFN- $\gamma(\mathrm{pg} / \mathrm{mL})$} \\
\hline $\mathrm{x}(\mathrm{SD})$ & $14.24(4.45)$ & $11.19(5.49)$ & \multirow{3}{*}{$\begin{array}{c}\mathrm{t}=1.30 \\
\mathrm{p}=0.210\end{array}$} \\
\hline Range & $8.39-23.11$ & $3.88-21.4$ & \\
\hline Median & 15.18 & 9.43 & \\
\hline \multicolumn{4}{|c|}{ IL-4 (pg/mL) } \\
\hline $\mathrm{x}(\mathrm{SD})$ & $0.119(0.015)$ & $0.125(0.027)$ & \multirow{3}{*}{$\begin{array}{c}\mathrm{Z}_{\mathrm{M}-\mathrm{W}}=0.67 \\
\mathrm{p}=0.510\end{array}$} \\
\hline Range & $0.110-0.154$ & $0.110-0.203$ & \\
\hline Median & 0.110 & 0.112 & \\
\hline \multicolumn{4}{|c|}{ VCAM-1 (ng/mL) } \\
\hline $\mathrm{x}(\mathrm{SD})$ & $966.6(89.6)$ & $1031.0(102.0)$ & \multirow{3}{*}{$\begin{array}{c}\mathrm{t}=1.64 \\
\mathrm{p}=0.116\end{array}$} \\
\hline Range & $832.6-1158.6$ & $924.4-1171$ & \\
\hline Median & 976.4 & 992.6 & \\
\hline \multicolumn{4}{|c|}{ Non-abortion (Control) } \\
\hline $\mathrm{n}$ & 21 & 17 & \\
\hline \multicolumn{4}{|c|}{ SOD (U/gHb) } \\
\hline $\mathrm{x}(\mathrm{SD})$ & 1208.9 (258.5) & $1285.1(244.0)$ & \multirow{3}{*}{$\begin{array}{c}\mathrm{t}=0.93 \\
\mathrm{p}=0.360\end{array}$} \\
\hline Range & $628-1697$ & $1008-1875$ & \\
\hline Median & 1244 & 1266 & \\
\hline \multicolumn{4}{|c|}{ IFN- $\gamma(\mathrm{pg} / \mathrm{mL})$} \\
\hline $\mathrm{x}(\mathrm{SD})$ & $2.89(2.47)$ & $3.94(4.65)$ & \multirow{3}{*}{$\begin{array}{c}\mathrm{Z}_{\mathrm{M}-\mathrm{W}}=0.470 \\
\mathrm{p}=0.636\end{array}$} \\
\hline Range & $0.39-11.89$ & $0.39-14.83$ & \\
\hline Median & 2.14 & 2.39 & \\
\hline \multicolumn{4}{|c|}{ IL-4 (pg/mL) } \\
\hline $\mathrm{x}(\mathrm{SD})$ & $0.683(0.519)$ & $0.552(0.414)$ & \multirow{3}{*}{$\begin{array}{c}\mathrm{Z}_{\mathrm{M}-\mathrm{w}}=0.793 \\
\mathrm{p}=0.428\end{array}$} \\
\hline Range & $0.22-1.746$ & $0.19-1.651$ & \\
\hline Median & 0.454 & 0.426 & \\
\hline \multicolumn{4}{|c|}{ VCAM-1 (ng/mL) } \\
\hline $\mathrm{x}(\mathrm{SD})$ & $576.6(139.4)$ & $620.3(164.9)$ & \multirow{3}{*}{$\begin{array}{c}\mathrm{Z}_{\mathrm{M}-\mathrm{W}}=1.395 \\
\mathrm{p}=0.163\end{array}$} \\
\hline Range & $404.4-970$ & $189.4-922.8$ & \\
\hline Median & 543.2 & 634.8 & \\
\hline \multicolumn{4}{|l|}{ DSA RI } \\
\hline $\mathrm{x}(\mathrm{SD})$ & $0.49(0.10)$ & $0.49(0.06)$ & \multirow{3}{*}{$\begin{array}{c}\mathrm{t}=0.34 \\
\mathrm{p}=0.746\end{array}$} \\
\hline Range & $0.33-0.74$ & $0.41-0.69$ & \\
\hline Median & 0.58 & 0.58 & \\
\hline
\end{tabular}

$\mathrm{Z}_{\mathrm{M}-\mathrm{W}}=$ Mann-Whitney test, $\mathrm{t}=\mathrm{t}$ test. 
Table 3. Correlation of various variables based on the intersection points of abortion incidence in the two groups $(n=60)$.

\begin{tabular}{|c|c|c|c|c|c|c|c|}
\hline \multirow{2}{*}{ Variables } & \multirow{2}{*}{ Cut-off points } & \multicolumn{2}{|c|}{ Abortion } & \multirow{2}{*}{$\mathrm{p}$ values } & \multirow{2}{*}{$\begin{array}{c}\text { Sensitivity } \\
(\%)\end{array}$} & \multirow{2}{*}{$\begin{array}{c}\text { Specificity } \\
\text { (\%) }\end{array}$} & \multirow{2}{*}{$\begin{array}{c}\text { Accuracy } \\
\text { (\%) }\end{array}$} \\
\hline & & Yes & No & & & & \\
\hline SOD (U/gHb) & $\leq 992$ & $\begin{array}{c}22 \\
-\end{array}$ & $\begin{array}{c}4 \\
34\end{array}$ & $<0.001$ & 100 & 89.5 & 93.3 \\
\hline $\mathrm{IFN}-\gamma(\mathrm{pg} / \mathrm{mL})$ & $\geq 3.58$ & $\begin{array}{c}22 \\
-\end{array}$ & $\begin{array}{c}7 \\
31\end{array}$ & $<0.001$ & 100 & 81.6 & 88.3 \\
\hline IL-4 (pg/mL) & $\leq 0.203$ & $\begin{array}{c}22 \\
-\end{array}$ & $\begin{array}{c}1 \\
37\end{array}$ & $<0.001$ & 100 & 97.4 & 98.3 \\
\hline VICAM-1 (ng/mL) & $\geq 788.6$ & $\begin{array}{c}22 \\
-\end{array}$ & $\begin{array}{c}4 \\
34\end{array}$ & $<0.001$ & 100 & 89.5 & 93.3 \\
\hline DSA RI & $\geq 0.55$ & $\begin{array}{c}22 \\
-\end{array}$ & $\begin{array}{c}33 \\
5\end{array}$ & 0.002 & 100 & 13.2 & 45.0 \\
\hline
\end{tabular}

Cut-off (intersection) points were obtained from rreceiver operating characteristic (ROC) curves.

Table 4. The percentage of changes of various variables which were measured in the two groups after vitamin $\mathrm{C}$ and placebo administration.

\begin{tabular}{|c|c|c|c|c|}
\hline \multirow[b]{2}{*}{ Variables } & \multicolumn{2}{|c|}{ Treatments } & \multirow[b]{2}{*}{$\mathrm{Z}_{\mathrm{M}-\mathrm{W}}$} & \multirow[b]{2}{*}{$\mathrm{p}$ values } \\
\hline & $\begin{array}{l}\text { Vitamin C } \\
(\mathrm{n}=30) \%\end{array}$ & $\begin{array}{c}\text { Placebo } \\
(\mathrm{n}=30) \%\end{array}$ & & \\
\hline SOD & 6.8 & 4 & 0.044 & 0.483 \\
\hline IFN- $\gamma$ & 15.7 & 45.9 & 1.397 & 0.081 \\
\hline IL-4 & 60.7 & 14.8 & 2.062 & 0.019 \\
\hline VCAM-1 & -2.2 & 5.5 & 1.685 & 0.046 \\
\hline DSA RI & -27.7 & -22.6 & ${ }^{*} 1.23$ & 0.113 \\
\hline
\end{tabular}

$\mathrm{Z}_{\mathrm{M}-\mathrm{W}}=$ Mann-Whitney test. $* \mathrm{t}=\mathrm{t}$ test. Percentage $=($ after - before $) /$ before $\times 100 \%$. Positive $=$ increase. Negative $=$ decrease .

Figure 1 shows the changes of SOD and IFN- $\gamma$ levels, with a negative correlation and a significant difference.

Figure 2 shows the changes of SOD and IL-4 levels with a positive correlation and a highly significant difference.

Figure 3 shows the changes of SOD and VCAM- 1 levels with a negative correlation and a highly significant difference.

Figure 4 shows the changes of SOD and DSA RI levels with a negative correlation. A significant difference is found in vitamin $\mathrm{C}$ group.

Table 5 shows the conditions before and after vitamin $\mathrm{C}$ administration. In the abortion group there was a decrease in SOD and IL-4 levels as well as an increase in IFN- $\gamma$ and VCAM-1 levels which showed a significant difference. In the group without abortion there was an increase in SOD and IL-4 levels and a decrease in IFN- $\gamma$, VCAM-1, and DSA RI levels, which showed a highly significant difference.

Table 6 shows the conditions before and after placebo administration. In abortion group there was a decrease in SOD and IL-4 levels and an increase in IFN- $\gamma$ and VCAM-1 levels which showed a significant difference. In the group without abortion there was no significant differences in the levels of SOD, IFN- $\gamma$, IL-4, VCAM-1, and DSA RI ( $>$ > 0.05).

\section{Discussion}

The selection of patients included into this study was done based on the following considerations: to get imminent abortion patients as many as possible, while getting rid of confounding factors such as aneuploidy congenital abnormalities in the fetus, uterine abnormalities, maternal body mass index, infectious diseases, chronic diseases such maternal kidney disease, heart disease, hypertension, diabetes mellitus, hypothyroidism, peptic ulcer, smoking and alcohol drinking habit, as well as a tough job. Nonetheless, removing other con- 


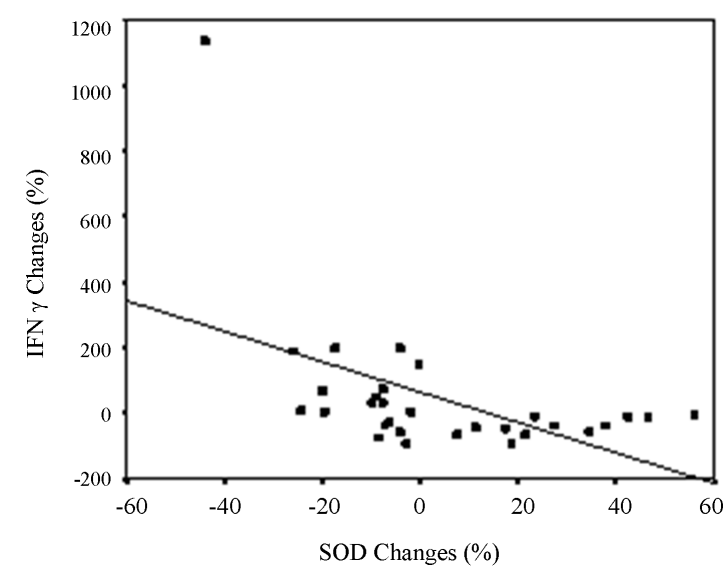

(a)

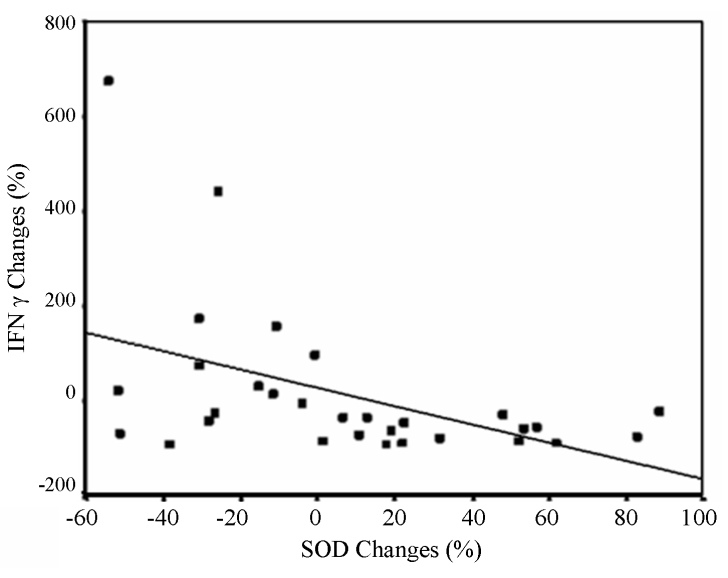

(b)

Figure 1. Correlation between changes of SOD and IFN- $\gamma$ levels in the two groups after vitamin $\mathrm{C}$ and placebo administration. (a) Vitamin C ( $\left.\mathrm{r}_{\mathrm{s}}=-0.523, \mathrm{p}=0.003\right)$; (b) Placebo $\left(\mathrm{r}_{\mathrm{s}}=-0.487, \mathrm{p}=0.006\right)$.

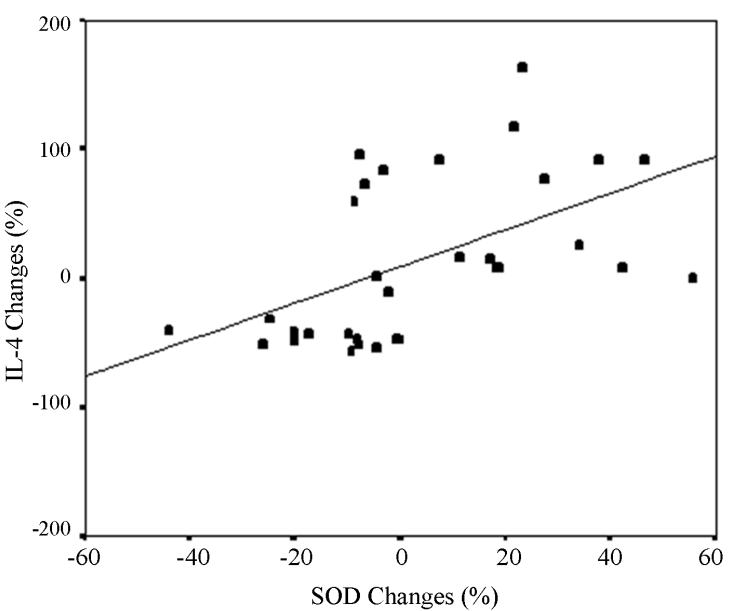

(a)

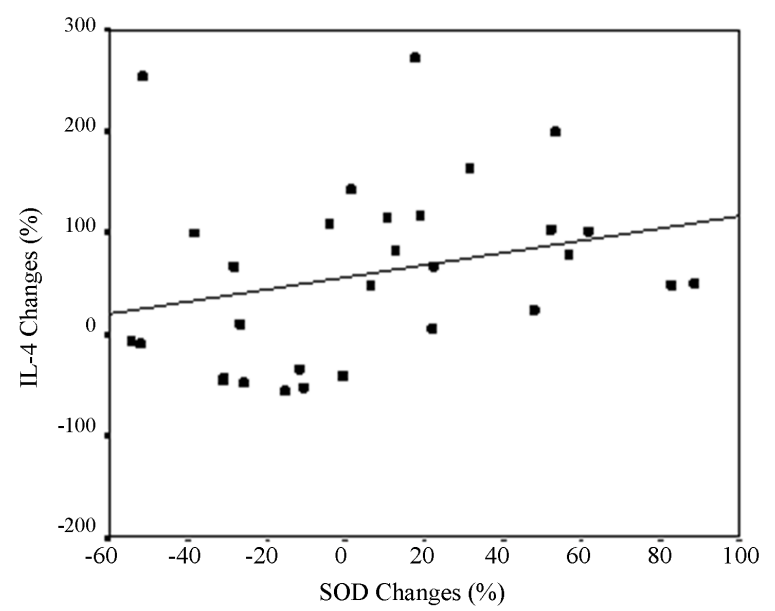

(b)

Figure 2. Correlation between changes of SOD and IL-4 levels in the two groups after vitamin C and placebo administration. (a) Vitamin C ( $\left.\mathrm{r}_{\mathrm{s}}=0.597, \mathrm{p}<0.001\right)$; (b) Placebo $\left(\mathrm{r}_{\mathrm{s}}=0.377, \mathrm{p}=0.040\right)$.

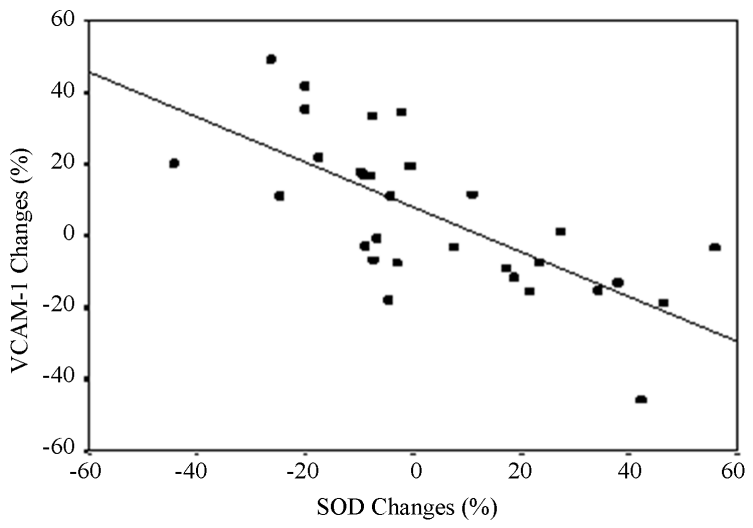

(a)

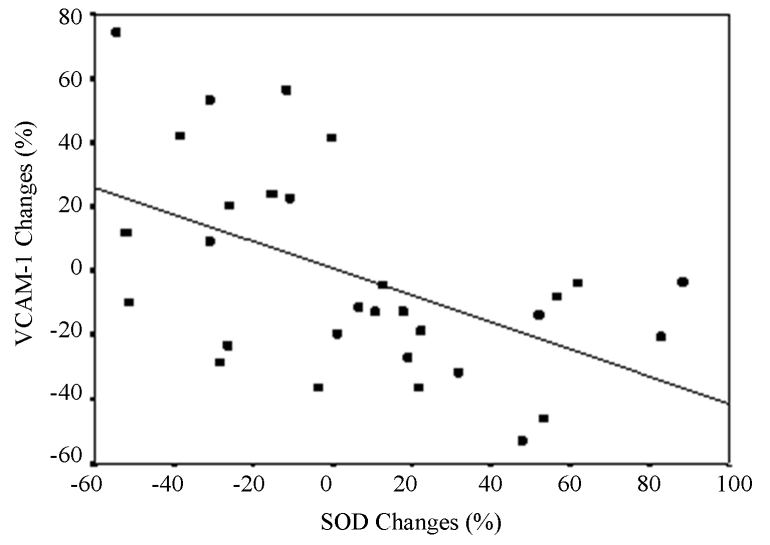

(b)

Figure 3. Correlation between the changes of SOD and VCAM-1 levels in the two grups after vitamin C and placebo administration. (a) Vitamin C $\left(\mathrm{r}_{\mathrm{s}}=-0.737, \mathrm{p}<0.001\right)$; (b) Placebo $\left(\mathrm{r}_{\mathrm{s}}=-0.737, \mathrm{p}=0.005\right)$. 


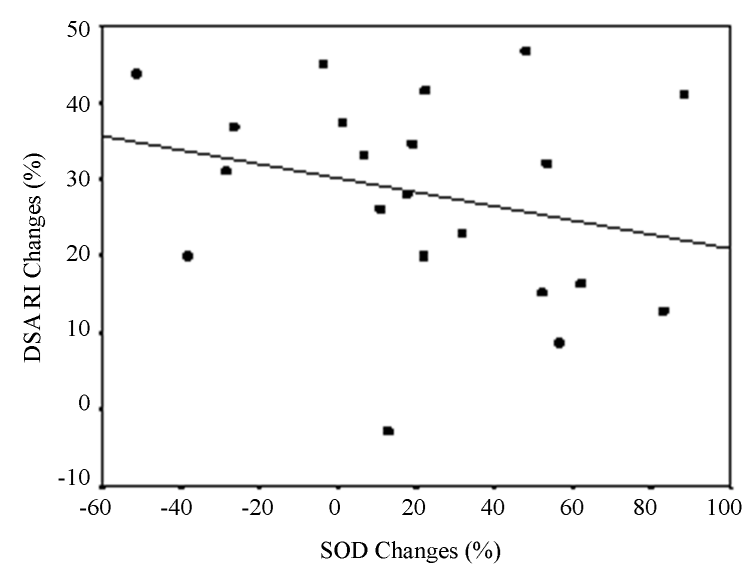

(a)

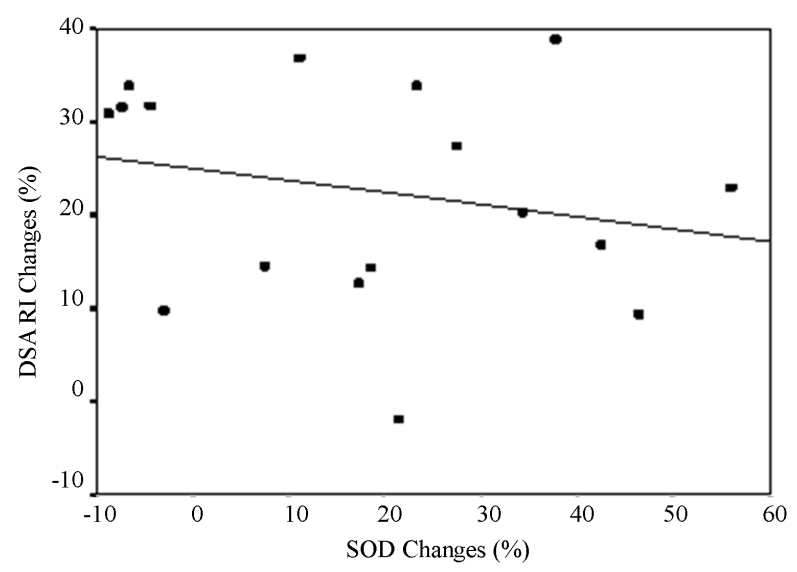

(b)

Figure 4. Correlation between the changes of SOD and DSA RI levels in the two groups after vitamin C and placebo administration. (a) Vitamin C $\left(\mathrm{r}_{\mathrm{s}}=-0.208, \mathrm{p}=0.022\right)$; (b) Placebo $\left(\mathrm{r}_{\mathrm{s}}=-0.310, \mathrm{p}=0.171\right)$.

founding factors was performed using stratified random sampling method. These factors included maternal age, parity, and gestational age at the time of the study. These three factors were considered as factors that were most likely to be confounders in this study.

In addition to age, parity, and gestational age there were many more factors that can affect the validity of this study such as ethnicity, blood type, environmental factors, and socioeconomic. However, given the minimum requirements in obtaining the sufficient internal and external validity to meet the target population, only those factors above were chosen to be removed by means of randomization. Selection of candidates into treatment and control groups was done by permuted-block randomization and was expected to provide equal opportunities to all candidates who have a wide variety of confounding factors to spread evenly into two groups. Although this research has made efforts to get rid of confounding factors by means of randomization, as well as inclusion and exclusion criteria determination, but not entirely perfect. The examination of chronic disease in the mother eg. kidney disease, heart disease, hypertension, diabetes mellitus, hypothyroidism, and peptic ulcer were done only based on anamnesis and clinical examination without further laboratory examination due to costs, time, and other factors.

Table 1 presents the characteristics of the subjects that include maternal age, parity and gestational age at the time of the study. In both groups in terms of maternal age, gestational age and parity, no significant differences were found, so the data were feasible to be compared. In this study, maternal age was restricted to be less than 30 years. In pregnant women younger than 30 years, the incidence of chromosomal abnormalities was less than $20 \%-30 \%$, while the more increasing maternal age, the incidence of chromosomal abnormalities will also increase [1]. In this study, the gestational age was 10 - 12 weeks with living fetuses and without congenital abnormalities by ultrasound. This examination was performed because in the gestational age above 10 weeks the incidence of chromosomal abnormalities is about 10\% - 20\% [1] [2].

Table 2 shows a comparison between two groups of subject. After vitamin $\mathrm{C}$ and placebo administration, there were significant differences in the levels of SOD. The level of SOD after vitamin C administration was 655.8 (163.6) U/gHb, whereas after placebo administration was 824.5 (106.7) U/gHb. It was significantly different $(p=0.008)$. It was proved that SOD plays an important role in the incidence of abortion and as it is seen in Table 3, the point of intersection of SOD to predict the occurrence of abortion is $\leq 992 \mathrm{U} / \mathrm{gHb}$. Therefore, it is obvious that if the SOD value is under the point of intersection, then abortion will occur. It is proved that for early diagnosis of imminent abortion, SOD levels can be used. SOD is an antioxidant enzyme in red blood cells that serves as superoxide radical catalysts into $\mathrm{H}_{2} \mathrm{O}_{2}$ and $\mathrm{O}_{2}^{-}$. Jenkins et al. [2] examines the role of antioxidants in healthy pregnant women who undergo abortion in the first trimester. The results indicated that if a blood sample was taken at the time of pregnancy and the pregnancy succeeded, it was associated to the increased levels of ceruloplasmin and SOD in the early first trimester. These changes led to the protection of cells from damage caused by the increased oxidative stress associated to pregnancy. Women who had miscarriage in the first trimester would have a significantly decreased SOD level. The decreased level of SOD caused by mitochondrial 
Table 5. The comparison of various variables before and after vitamin $\mathrm{C}$ administration in the two groups.

\begin{tabular}{|c|c|c|c|}
\hline \multirow{2}{*}{ Variables } & \multicolumn{2}{|c|}{ Vitamin C administrations } & \multirow{2}{*}{ Significance } \\
\hline & Before & After & \\
\hline \multicolumn{4}{|c|}{ Abortion $(\mathrm{n}=9)$} \\
\hline \multicolumn{4}{|c|}{ SOD (U/gHb) } \\
\hline $\mathrm{x}(\mathrm{SD})$ & $900.9(146.8)$ & $655.8(163.6)$ & \multirow{3}{*}{$\begin{array}{c}\mathrm{t}_{\text {paired }}=3.93 \\
\mathrm{p}=0.004\end{array}$} \\
\hline Range & $649-1102$ & $460-983$ & \\
\hline Median & 964.0 & 659 & \\
\hline \multicolumn{4}{|c|}{ IFN- $\gamma(\mathrm{pg} / \mathrm{mL})$} \\
\hline $\mathrm{x}(\mathrm{SD})$ & $7.49(4.45)$ & $14.24(4.45)$ & \multirow{3}{*}{$\begin{array}{c}\mathrm{t}_{\text {paired }}=4.76 \\
\mathrm{p}=0.001\end{array}$} \\
\hline Range & $1.15-13.96$ & $8.39-23.11$ & \\
\hline Median & 7.89 & 15.18 & \\
\hline \multicolumn{4}{|c|}{ IL-4 (pg/mL) } \\
\hline $\mathrm{x}(\mathrm{SD})$ & $0.198(0.038)$ & $0.119(0.015)$ & \multirow{3}{*}{$\begin{array}{c}\mathrm{Z}_{\mathrm{W}}=2.666 \\
\mathrm{p}=0.008\end{array}$} \\
\hline Range & $0.121-0.248)$ & $0.11-0.154$ & \\
\hline Median & 0.21 & 0.11 & \\
\hline \multicolumn{4}{|c|}{ VCAM-1 (ng/mL) } \\
\hline $\mathrm{x}(\mathrm{SD})$ & 735.5 (136.3) & 966.6 (89.6) & $\mathrm{t}_{\text {paired }}=6.13$ \\
\hline Range & 477.8 - 893.4 & 832.6 - 1158.6 & \multirow[t]{2}{*}{$\mathrm{p}=<0.001$} \\
\hline Median & 751.6 & 976.4 & \\
\hline \multicolumn{4}{|c|}{ Non-abortion (control) $(\mathrm{n}=21)$} \\
\hline \multicolumn{4}{|c|}{ SOD (U/gHb) } \\
\hline $\mathrm{x}(\mathrm{SD})$ & 1046 (177.5) & $1208.9(258.5)$ & \multirow{3}{*}{$\begin{array}{c}\mathrm{t}_{\text {paired }}=1.97 \\
\mathrm{p}=0.013\end{array}$} \\
\hline Range & $669-1368$ & $628-1697$ & \\
\hline Median & 1017 & 1244 & \\
\hline \multicolumn{4}{|c|}{ IFN- $\gamma(\mathrm{pg} / \mathrm{mL})$} \\
\hline $\mathrm{x}(\mathrm{SD})$ & $7.18(5.35)$ & $2.89(2.47)$ & \multirow{3}{*}{$\begin{array}{l}\mathrm{Z}_{\mathrm{W}}=4.017 \\
\mathrm{p}=<0.001\end{array}$} \\
\hline Range & $1.26-22$ & $0.39-11.89$ & \\
\hline Median & 5.59 & 2.14 & \\
\hline \multicolumn{4}{|c|}{ IL-4 (pg/mL) } \\
\hline $\mathrm{x}(\mathrm{SD})$ & $0.383(0.330)$ & $0.683(0.519)$ & $\mathrm{Z}_{\mathrm{W}}=4.014$ \\
\hline Range & $0.11-1.25$ & $0.22-1.746$ & \multirow[t]{2}{*}{$\mathrm{p} \leq 0.001$} \\
\hline Median & 0.242 & 0.454 & \\
\hline \multicolumn{4}{|c|}{ VCAM-1 (ng/mL) } \\
\hline $\mathrm{x}(\mathrm{SD})$ & 731.1 (206.2) & $576.6(139.4)$ & $\mathrm{t}_{\text {paired }}=3.597$ \\
\hline Range & 354.2 - 1195.2 & $404.4-970$ & \multirow[t]{2}{*}{$\mathrm{p} \leq 0.001$} \\
\hline Median & 681.2 & 543.2 & \\
\hline \multicolumn{4}{|l|}{ DSA RI } \\
\hline $\mathrm{x}(\mathrm{SD})$ & $0.66(0.11)$ & $0.49(0.10)$ & \multirow{3}{*}{$\begin{array}{c}\mathrm{t}_{\text {paired }}=8.20 \\
\mathrm{p} \leq 0.001\end{array}$} \\
\hline Range & $0.45-0.82$ & $0.33-0.74$ & \\
\hline Median & 0.65 & 0.58 & \\
\hline
\end{tabular}

$\mathrm{Z}_{\mathrm{W}}=$ Wilcoxon test. $\mathrm{t}_{\text {pared }}=$ paired $\mathrm{t}$ test.

respiratory chain electron excitation, and unused $\mathrm{O}_{2}^{-}$ions can increase the production of reactive oxygen species (ROS). This change was found in the peripheral circulation and may reflect changes that occur in the uterus [3]. First trimester of pregnancy that was continued associated to the increased antioxidant 
Table 6. Comparison of various variables before and after placebo administration in the two groups.

\begin{tabular}{|c|c|c|c|}
\hline \multirow{2}{*}{ Variables } & \multicolumn{2}{|c|}{ Placebo administrations } & \multirow{2}{*}{ Significance } \\
\hline & Before & After & \\
\hline \multicolumn{4}{|c|}{ Abortion $(n=13)$} \\
\hline \multicolumn{4}{|c|}{$\mathrm{SOD}(\mathrm{U} / \mathrm{gHb})$} \\
\hline $\mathrm{x}(\mathrm{SD})$ & $974.9(89.1)$ & $824.5(106.7)$ & \multirow{3}{*}{$\begin{array}{c}\mathrm{t}_{\text {paired }}=4.15 \\
\mathrm{p}=0.001\end{array}$} \\
\hline Range & $764-1107$ & $598-992$ & \\
\hline Median & 970 & 835 & \\
\hline \multicolumn{4}{|c|}{ IFN- $\gamma(\mathrm{pg} / \mathrm{mL})$} \\
\hline $\mathrm{x}(\mathrm{SD})$ & $6.69(5.26)$ & $11.19(5.49)$ & \multirow{3}{*}{$\begin{array}{c}\mathrm{Z}_{\mathrm{W}}=3.180 \\
\mathrm{p}=0.002\end{array}$} \\
\hline Range & $0.68-20.80$ & $3.88-21.4$ & \\
\hline Median & 5.39 & 9.43 & \\
\hline \multicolumn{4}{|c|}{ IL-4 (pg/mL) } \\
\hline $\mathrm{x}(\mathrm{SD})$ & $0.225(0.029)$ & $0.125(0.027)$ & \multirow{3}{*}{$\begin{array}{c}\mathrm{Z}_{\mathrm{W}}=3.180 \\
\mathrm{p}=0.002\end{array}$} \\
\hline Range & $0.188-0.281$ & $0.11-0.203$ & \\
\hline Median & 0.222 & 0.112 & \\
\hline \multicolumn{4}{|c|}{ VCAM-1 (ng/mL) } \\
\hline $\mathrm{x}(\mathrm{SD})$ & $828.1(96.1)$ & $1031.0(102.0)$ & \multirow{3}{*}{$\begin{array}{c}\mathrm{Z}_{\mathrm{W}}=3.180 \\
\mathrm{p}=0.002\end{array}$} \\
\hline Range & $665.8-992.8$ & 924.4 - 1171 & \\
\hline Median & 821.8 & 992.6 & \\
\hline \multicolumn{4}{|c|}{ Non-abortion (control) $(\mathrm{n}=17)$} \\
\hline \multicolumn{4}{|c|}{$\mathrm{SOD}(\mathrm{U} / \mathrm{gHb})$} \\
\hline $\mathrm{x}(\mathrm{SD})$ & $1106.4(244.3)$ & $1285.1(244.0)$ & \multirow{3}{*}{$\begin{array}{c}\mathrm{t}_{\text {paired }}=0.79 \\
\mathrm{p}=0.439\end{array}$} \\
\hline Range & $732-1628$ & $1008-1875$ & \\
\hline Median & 1079 & 1266 & \\
\hline \multicolumn{4}{|c|}{ IFN- $\gamma(\mathrm{pg} / \mathrm{mL})$} \\
\hline $\mathrm{x}(\mathrm{SD})$ & $3.33(7.69)$ & $3.94(4.65)$ & \multirow{3}{*}{$\begin{array}{c}\mathrm{Z}_{\mathrm{W}}=0.113 \\
\mathrm{p}=0.910\end{array}$} \\
\hline Range & $2.23-23$ & $0.39-14.83$ & \\
\hline Median & 3.39 & 2.39 & \\
\hline \multicolumn{4}{|c|}{ IL-4 (pg/mL) } \\
\hline $\mathrm{x}(\mathrm{SD})$ & $0.476(0.414)$ & $0.552(0.414)$ & $\mathrm{Z}_{\mathrm{W}}=0.833$ \\
\hline Range & $0.110-1.522$ & $0.19-1.651$ & \multirow[t]{2}{*}{$\mathrm{p}=0.405$} \\
\hline Median & 0.458 & 0.426 & \\
\hline \multicolumn{4}{|c|}{ VCAM-1 (ng/mL) } \\
\hline x (SD) & 689.0 (194.7) & $620.3(164.9)$ & \multirow{3}{*}{$\begin{array}{c}\mathrm{Z}_{\mathrm{W}}=1.388 \\
\mathrm{p}=0.165\end{array}$} \\
\hline Range & 348.6 - 1121.4 & 189.4 - 922.8 & \\
\hline Median & 687 & 634.8 & \\
\hline \multicolumn{4}{|l|}{ DSA RI } \\
\hline $\mathrm{x}(\mathrm{SD})$ & $0.57(0.07)$ & $0.49(0.06)$ & \multirow{3}{*}{$\begin{array}{c}\mathrm{t}_{\text {paired }}=2.40 \\
\mathrm{p}=0.112\end{array}$} \\
\hline Range & $0.43-0.76$ & $0.41-0.69$ & \\
\hline Median & 0.62 & 0.58 & \\
\hline
\end{tabular}

$\mathrm{Z}_{\mathrm{W}}=$ Wilcoxon test. $\mathrm{t}_{\text {paired }}=$ paired $\mathrm{t}$ test.

activity as shown in the increased level of ceruloplasmin and SOD, and it can provide antioxidant protection. The decreased level of SOD in women who undergo abortion, suggesting that abortion is triggered by a specific event. These changes indicate that early pregnancy is associated to increased oxidative stress, but the damage 
can be avoided because of the antioxidant system. In patients who undergo abortion, the decreased level of unused $\mathrm{O}_{2}^{-}$ions can increase ROS production [4].

Table 3 shows the intersection point of the various measured variables that can predict the occurrence of abortion. The sensitivity, specificity, and accuracy in the intersection point of SOD, IFN- $\gamma$, IL-4, and VICAM-1 (chemical examination) is quite high, while the sensitivity in the intersection point of DSA RI is high, but the specificity is low with $45 \%$ accuracy. In this study, the points of intersection for abortion are: SOD level $\leq 992$ $\mathrm{U} / \mathrm{gHb}, \mathrm{IFN}-\gamma>3.58 \mathrm{pg} / \mathrm{mL}$, IL-4 $\leq 0.203 \mathrm{pg} / \mathrm{mL}$, and VICAM-1 $>788.6 \mathrm{ng} / \mathrm{mL}$, with quite high sensitivity, specificity, and accuracy. Some researchers also stated that biochemical examination gave quite high level of sensitivity, specificity, and accuracy [3] [4]. Although the sensitivity, specificity, and accuracy are quite high for the chemical examination, but the cost is also much more expensive than a non-chemical examination. So that for the diagnosis of imminent abortion and to predict the occurrence of abortion, DSA RI examination by ultrasound can also be used as a cheaper alternative, despite its low specificity with an intersection point $\geq 0.55$. In this study, the intersection point was lower than previous study with the intersection point of DSA RI $\geq 0.6$ [5].

Table 4 shows the group after vitamin $\mathrm{C}$ administration. There is an increase in the percentage of IL-4 level by $60.7 \%$ and a decrease in the percentage of VCAM-1 level by $-2.2 \%$ which are significantly different. It is proved that the antioxidant vitamin $\mathrm{C}$ administration plays a role in the improvement of the immune system, as evidenced by the presence of elevated levels of IL-4. It seems that vitamin C plays a role in suppressing oxidative stress by increasing SOD level and IL-4 level immunologically. This is related to the role of vitamin C which is a water-soluble antioxidant that has a particularly significant function in the cell membrane and system vascular improvement [2]. Vitamin C also maintains humoral and cellular immune responses in vivo and in vitro [6]. This immunological change also affects the improvement of endothelial damage that is proved by the decreased level of VCAM-1. Antioxidant vitamin C also protects against excessive production of ROS [7]. When the balance between ROS and protection mechanisms shifts toward prooxidant, excessive ROS will arise and damage will occur. Damage caused by free radicals (oxidative stress) and lipid peroxidation is involved in the pathophysiology of a various clinical circumstances [8]. Women who undergo abortions will have a significantly lower level of total thiol, ceruloplasmin, ascorbic acid, $\alpha$-tocopherol, and erythrocyte glutathione than control group. It supports an evidence of increased lipid peroxydation [4] [7]. These results also showed that in women who undergo abortion there is an imbalance of redox status with prooxidative activity, and increased oxidative stress may be the cause of abortus [2] [6]. Pregnancy is also associated with some degree of oxidative stress. In a continued pregnancy, changes in the level of antioxidants occur to protect pregnancy against increased oxydative stress [9].

Figures 1-4 show the changes in SOD levels that show a negative correlation with the level of IFN- $\gamma$, VCAM-1, and DSA RI in both groups after vitamin C and placebo administration, while the IL-4 show a positive correlation. Oxidative stress characterized by a decrease in the levels of SOD in iminnent abortion causes a decreased immune system which is characterized by an increase level of IFN- $\gamma$ and a decrease level of IL-4. A decrease level of SOD also causes endothelial damage which is characterized by the increase level of molecular VCAM-1 and clinical DSA RI. It proves that in imminent abortion there is an increase of oxidative stress. Increased oxidative stress resulting in an increase of free radicals that subsequently cause damage and lipid peroxidation production in pathophysiology of a various clinical circumstances. The decrease of SOD level causes endothelial damage. In the immunological pathway of Th1 there is an increase of embryotoxic IFN- $\gamma$, whereas in the immunological pathway of Th2 there is a decrease of IL-4 level. Vives et al. [8] examined cytokine expression in the decidua and trophoblast tissue. The result showed a significantly increased level of IFN- $\gamma$ in decidual tissue of women who undergo abortion. These findings indicate the a balance between Th1 and Th2 cytokines during pregnancy which are shown in the balanced level of IFN- $\gamma$ and IL-4 in fetal maternal relationship [4] [9].

Table 5 and Table 6 show the conditions before and after vitamin $\mathrm{C}$ and placebo administration in the two groups of study. In the abortion group, vitamin C administration caused a decreased level of SOD and IL-4 as well as an increased level of IFN- $\gamma$ and VCAM-1, which showed a significant difference. In the control group, vitamin C administration led to an increased level of SOD and IL-4 as well as a decreased level of IFN- $\gamma$, VCAM-1, and DSA RI, which showed a highly significant difference. The placebo administration in abortion group led to a decreased level of SOD and IL-4 as well as an increased level of IFN- $\gamma$ and VCAM-1, which showed a significant difference. It shows that placebo administration can not raise the level of SOD and IL-4, so that pregnancy can not continue, whereas placebo administration in the control group showed no significant 
difference in the level of SOD, IFN- $\gamma$, IL-4, VCAM-1, and DSA RI. It proves that placebo administration did not play a role in the patophysiology of imminent abortion. Both tables show that vitamin $\mathrm{C}$ administration in imminent abortion plays role in the increase of antioxidant status molecularly, that is characterized by the increased level of SOD and immunological status by the increased level of IL-4 which can maintain pregnancy and prevent abortion. With the increased level of SOD that plays role in the reduction of oxidative stress, the vitamin C administration in imminent abortion also plays a role in the decreased level of IFN- $\gamma$, VCAM- 1 , and DSA RI so that can prevent the occurrence of abortion. The elevated level of IL-4 proves that vitamin C plays a role in immunological pathway of IL-4 which is found in Th1 pathway that maintains pregnancy. Some studies have also proven that vitamin $\mathrm{C}$ administration can maintain the humoral and cellular immune responses in vivo and in vitro [6]. The decreased level of IFN- $\gamma$, VCAM-1 and DSA RI were also associated with an improvement caused by antioxidant status. The researchers claimed vitamin $\mathrm{C}$ as a water-soluble antioxidant which has a significant function primarily in the cell membrane and the system vascular improvement [1] [2]. The immunological processes also occur in the decidua. Decidua is maternal tissue which is strongly associated with fetal trophoblast. The immunological interactions between mother and fetus occur within this tissue. Decidua contains a disproportionately high number of leukocytes, including macrophages and lymphocytes. Decidual lymphocytes may be cytotoxical againts trophoblast. In the imminent abortion, there is cell membranes damage in the endometrial lining that causes the increase of DSA [3] [10] [11]. This changes affect the pregnancy development [11] [12]. When the pregnancy continues, the level of DSA RI should decrease according to the increase of gestational age [13] [14], however in imminent abortion, the level of DSA RI increases. It causes the change in DSA RI flow that ultimately leads to abortion [3] [7].

\section{Conclusions}

1) There is a correlation between the increased level of SOD with the decreased level of IFN- $\gamma$ and the increased level of IL-4 in imminent abortion after vitamin C administration.

2) There is a correlation between the increased level of SOD with the decreased level of DSA RI and VCAM-1 in imminent abortion after vitamin $\mathrm{C}$ administration.

3) In the case of abortion, there is a decrease in the level of SOD and IL-4 as well as an increase in the level of IFN- $\gamma$, VCAM-1, and DSA RI.

\section{References}

[1] Cunningham, F.G., Leveno, K.J., Bloom, S.L., Hauth, J.C., Gilstrap III, L.C. and Wenstrom, K.D. (2005) Williams Obstetrics. 22nd Edition, McGraw Hill, New York.

[2] Jenkins, C., Wilson, R., Roberts, J., Miller, H., McKillop, J.H. and Walker, J.J. (2000) Antioxidants: Their Role in Pregnancy and Miscarriage. Antioxidants \& Redox Signaling, 24, 623-628. http://dx.doi.org/10.1089/15230860050192369

[3] Wilson, R. (2004) Antioxidants and Miscarriage. In: Wilson, W., Ed., Recurrent Abortus and Preeclampsia the Roles Played by the Immune System and Antioxidants, World Scientific, New Jersey, 83-101.

[4] Kupesic, S., Matijevic, R. and Kurjak, A. (2001) Early Pregnancy Loss. In: Kurjak, A.C. and Carrera, J.M., Eds., The Embryo as a Patient, The Parthenon Publishing Group, New York, 70-80.

[5] Wilson, R., Ling, H., MacLean, M.A., et al. (1999) Thyroid Antibody Titre and Avidity in Patients with Recurrent Miscarriage. Fertility and Sterility, 71, 558-561. http://dx.doi.org/10.1016/S0015-0282(98)00509-3

[6] Vural, P, Akgul, C., Yildirim, A. and Canbaz, M. (2000) Antioxidant Defence in Recurrent Abortion. Clinica Chimica Acta, 295, 169-177. http://dx.doi.org/10.1016/S0009-8981(99)00255-7

[7] Kurjak, A. and Kupesic, S. (1999) Blood Flow Studies in Early Pregnancy. In: Kurjak, A.K.S., Ed., Color Doppler in Obstetrics, Gynecology and Infertility, Art-Studio Azinovic-Medison, Zagreb-Seoul, 87-108.

[8] Vives, A., Balasch, J., Yague, J., Quinto, L., Ordi, J. and Vanrell, J.A. (1999) Type-1 and Type-2 Cytokines and Human Decidual Tissue and Trophoblasts from Normal and Abnormal Pregnancies Detected by Reverse Trancriptase Polymerase Chain Reaction (RT-PCR). American Journal of Reproductive Immunology, 42, 361-368. http://dx.doi.org/10.1111/j.1600-0897.1999.tb00113.x

[9] Jaffe, R. (1992) Color Doppler Imaging in Obstetrics and Gynecology. McGraw-Hill, New York.

[10] Narimoto, K., Noda, Y. and Shiotani, M. (1990) Immunohistochemical Assessment of Superoxide Dismutase Expression in the Human Endometrium throughout the Menstrual Cycle. Acta Histochemica et Cytochemica, 23, 487-498. 
http://dx.doi.org/10.1267/ahc.23.487

[11] Sugino, N., Nakamura, Y. and Takeda, O. (1995) Change in Activities of Superoxide Dismutase and Lipid Peroxide in Corpus Luteum during Pregnancy in Rats. Journal of Reproduction and Fertility, 97, 347-351. http://dx.doi.org/10.1530/jrf.0.0970347

[12] Sugino, N., Telleria, C.M. and Gibori, G. (1998) Differential Regulation of Copper-Zinc Superoxide Dismutase and Manganese Superoxide Dismutase in the Rat Corpus Luteum: Induction of Manganese Superoxide Dismutase Messenger Ribonucleic Acid by Inflamatory Cytokines. Biology of Reproduction, 59, 208-215. http://dx.doi.org/10.1095/biolreprod59.1.208

[13] Sugino, N., Shimamura, K. and Takiguchi, S. (1996) Changes in Activity of Superoxide Dismutase in the Human Endometrium throughout the Menstrual Cycle and in Early Pregnancy. Human Reproduction, 11, 1073-1078. http://dx.doi.org/10.1093/oxfordjournals.humrep.a019299

[14] Wilson, R., Moore, J. and Jenkin, C. (2003) Abnormal IL-2 Receptor Levels in Non Pregnant Women with a History of Recurrent Miscarriage. Human Reproduction, 18, 1529-1530. http://dx.doi.org/10.1093/humrep/deg287 
Scientific Research Publishing (SCIRP) is one of the largest Open Access journal publishers. It is currently publishing more than 200 open access, online, peer-reviewed journals covering a wide range of academic disciplines. SCIRP serves the worldwide academic communities and contributes to the progress and application of science with its publication.

Other selected journals from SCIRP are listed as below. Submit your manuscript to us via either submit@scirp.org or Online Submission Portal.
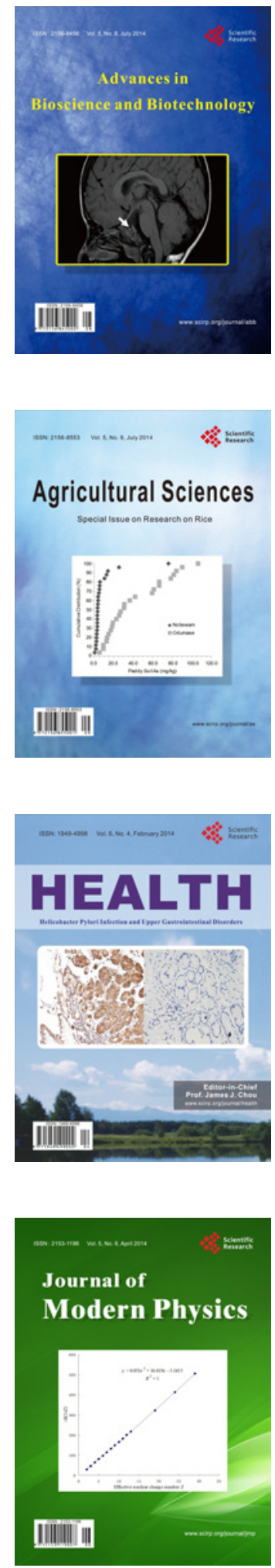
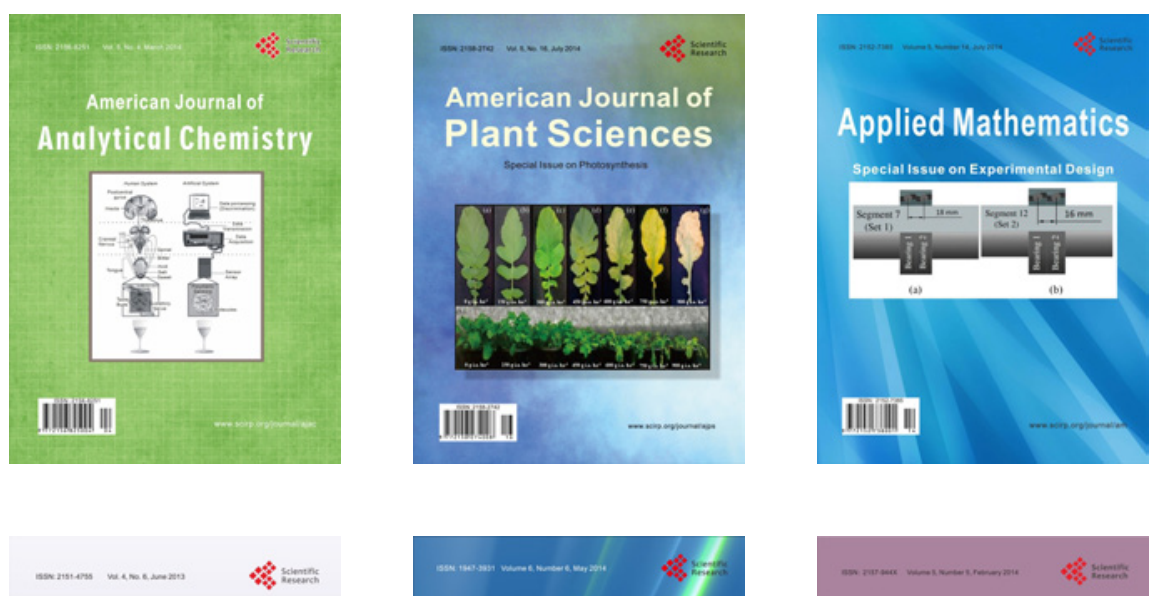

Creative Education
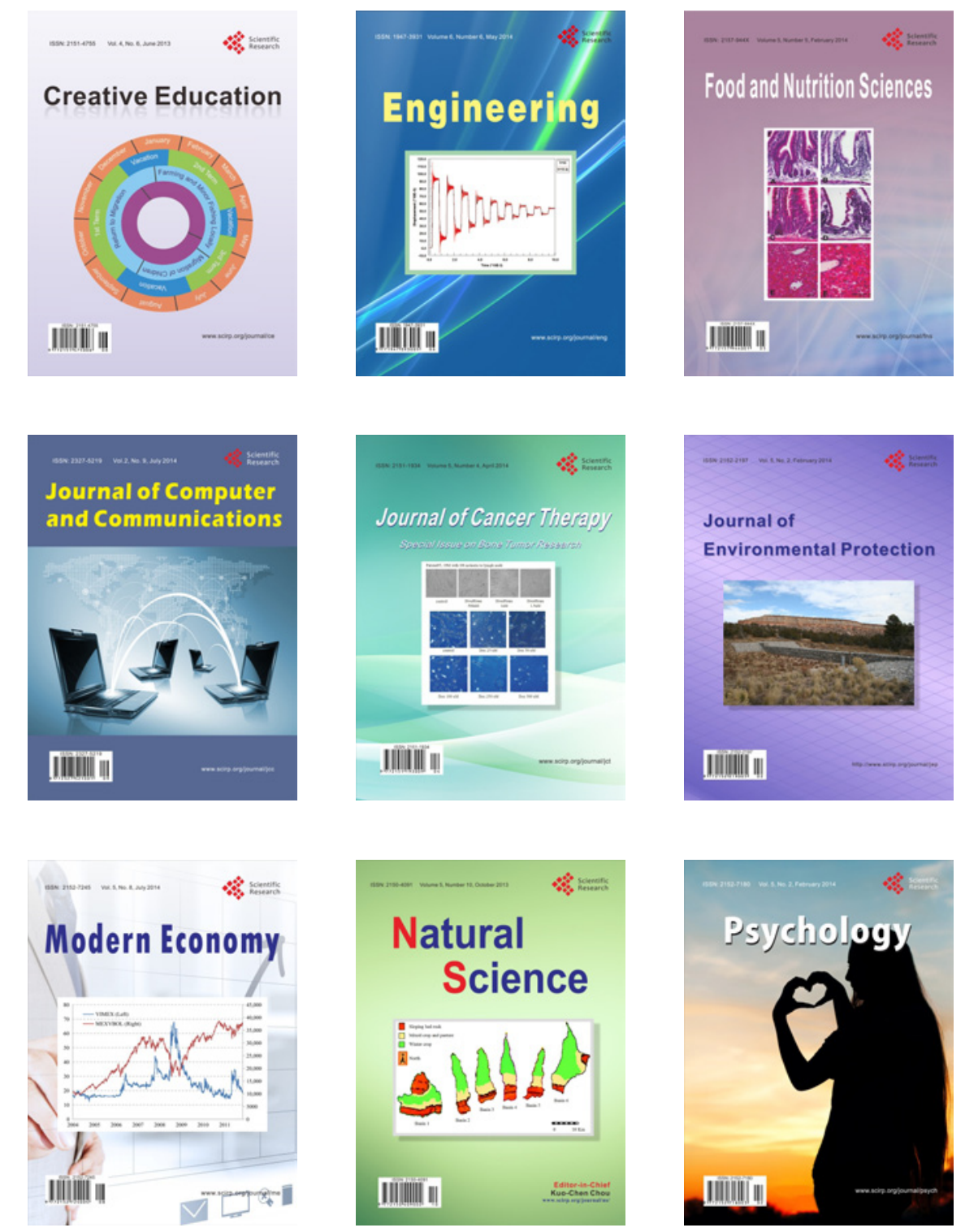